\title{
Sukumar Chandra Sirkar and the Department of Optics at the IACS
}

\author{
Rajinder Singh* \\ Institute of Physics, University of Oldenburg, Germany
}

(Received 02 August 2018)

\begin{abstract}
Sukumar Chandra Sirkar an unsung hero of 'Calcutta School of Physics' began his research career under C. V. Raman in the middle of 1920s. Sirkar witnessed the discovery of the Raman effect in 1928 and was the first person to study the intensity of Raman lines in Raman spectra. For more than half a century he was associated with the University of Calcutta and the Indian Association for the Cultivation of Science (IACS). Later, some of his students occupied higher positions in various institutions. Sirkar differed with his teacher C. V. Raman while interpreting the diffuse Laue spots observed in crystals. He was a Fellow of the Indian National Science Academy and associated with many other scientific institutions, such as Indian Science News Association and the journal Science and Culture. The paper attempts to highlight Sirkar's role in development of Department of Optics at the IACS.
\end{abstract}

Key words: C. V. Raman, G. S. Kastha, M. N. Saha, Raman effect, Raman lines, S. C. Sirkar.

\section{Introduction}

S. K. Mitra FRS, founder of the ionospheric science (Singh, 2014; Singh, 2017); D. M. Bose, the initiator of the particle physics research in India, ${ }^{1}$ and Bidhu Bhushan Ray, a pioneer of X-ray spectroscopy, ${ }^{2}$ are the unsung heroes of Indian science. Only, in recent years attempts have been made by present author and S. C. Roy to explore their lives and scientific work. Perhaps there is no book, which deals with Sukumar Chandra Sirkar's scientific work. The book 'A Century: Indian Association for Cultivation of Science' brought out on the occasion of

DOI: $10.16943 / \mathrm{ijhs} / 2019 / \mathrm{v} 54 \mathrm{i} 3 / 49743$

*Email: rajinder.singh@uni-oldenburg.de

${ }^{1}$ To know more about D. M. Bose, readers may look at the some literatures published recently (Singh, 2016; Roy and Singh, 2016; Roy and Singh, 2017; Singh and Roy, 2017).

${ }^{2}$ For more detail see, Singh, 2017. 100th anniversary of the IACS intermittently refers to the department of Optics, but says nothing in detail about the development of the Department and in particular, the role played by S. C. Sirkar (Ghatak et al., 1976). The present article is intended to fulfil the gap. To start with, a short biography of S. C. Sirkar is given. ${ }^{3}$

\section{Sukumar Chandra Sirkar - A short biography}

Sukumar Chandra Sirkar (abbrv. S. C. Sirkar or SCS) was born on April 18, 1898, in the village Kullya (now in Bangladesh). Sirkar was only twelve, when his father died and he was brought up by his mother Rajmohni. Sirkar

\footnotetext{
${ }^{3}$ The given biographical information is mainly based on Annual Reports of the IACS, Calcutta (abbrv. AR-IACS); Kashtha $(1983,1984)$ and Sirkar (1988, pp. 54-58).
} 


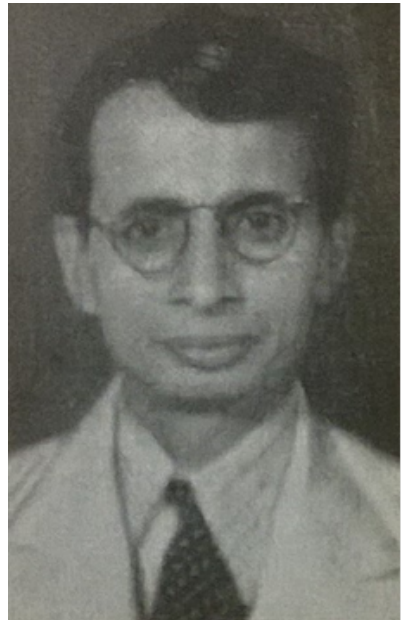

Figure 1 S. C. Sirkar (1898-1983); Credit: IACS.

completed his early education with the help of a local welloff person and even took up various jobs to earn a livelihood. At one time, he also started a small match box manufacturing factory but was unsuccessful. SCS served as an assistant Head Master at H. E. School, Chandan Nagar for a short period of three months. He appeared at competitive examination for recruitment in Bengal Civil Service; but left it without submitting the answer script (Kastha, 1984, pp. 1-4).

SCS obtained his B.Sc. degree in Physics Honours in 1920 securing 2nd position in First Class from the University of Calcutta. His Honours practical examiners were D. M. Bose, University College of Science, and P. C. Mahalanobis, Presidency College Calcutta. He was awarded D. C. Laha Scholarship of Rs. 40 per month. Instead of going for a M.Sc. degree SCS accepted a permanent job in the Bridge Engineering's Office at Paksey.

SCS came in contact with C. V. Raman for the first time in 1920 at IACS where Raman took classes on Electricity and Magnetism. His contact with two of Raman's research scholars, K. S. Krishnan (co-discoverer of the Raman effect $)^{4}$ and L. A. Ramdas motivated him to pursue research. In 1925, he passed M.Sc. (Physics) with 56\% marks in practical and thus was placed first in the Second class. His wish to work under Raman was not fulfilled as Raman took a candidate who stood first.

SCS married Manimala Sirkar in 1926 and the couple

${ }^{4}$ For Krishnan's biography see, Lonsdale et al., 1967; Mallik and Chatterjee, 2012. had four children. The family must have had a difficult life as he was not earning much as an Assistant. Raman saw the talent in Sirkar and offered him the Palit Scholarship for three years at the rate of Rs. 75 per month (Sirkar, 1988, pp. 54-58). SCS resigned the permanent job to join Raman's team in July 1926. About his duties he recalled:

I was first assigned the experimental investigation or [probably 'on' not 'or'] penetration of light in the second medium during total reflection. This work was completed in a month and I was next asked to determine the permanent electric moment of a few simple organic molecules by Debye's method. I set up the apparatus required for the heterodyne null method in the laboratory of the Association and got results for three simple organic molecules (Sirkar, 1988, pp. 54-58).

At the University College of Science, Sirkar's teachers were C. V. Raman, M. N. Saha, D. M. Bose and S. N. Bose. Sirkar's initial research work was on the electric moment of chemicals (Sirkar, 1928a), Kerr effect (Sirkar, 1928b; Raman and Sirkar, 1928) and Laue photographs of crystals (Sirkar, 1930). Raman suggested him to work on Laue patterns due to iridescent crystals of potassium chlorate. SCS published only one article on this topic as W. H. Zachariasen, USA, already published the work on potassium chlorate crystals, which he (SCS) was doing. This was informed to SCS by Raman after his return from Europe after receiving the Nobel Prize in 1931.

Three years after joining as Assistant Research Scholar, SCS still had not received D.Sc. degree. He explained the reasons as -Krishnan left the IACS in 1929 to become a Reader at the University of Dacca. Raman engaged him (SCS) to work on Raman effect in liquids and SCS specialized in Raman spectroscopy. However, he was not satisfied with the standard of the work done during 1930 and 1932, which was not worth of a degree. He did not reveal the facts but wrote: "By some coincidence of chance I had the opportunity of improving the standard of my work a few months later" (Sirkar, 1988, pp. 54-58).

In 1933, when Raman accepted the Directorship of the Indian Institute of Science (IISc) SCS submitted the D.Sc. thesis on "Method for measuring the relative intensities of Raman lines excited by the different radiations from visible to ultraviolet regions". It seems that he was not quite happy to see that Raman was one of the examiners. He 
stated that Raman "himself arranged for the appointment of examiners to adjudicate upon the thesis and as a special case got his name included in the list of three examiners, the other two of the list being Prof. [J. C.] McLennan of Toronto University and Prof. Peter Pringsheim of Germany." As Pringsheim declined, Raman got appointed Charles Fabry, Paris, in his place. It remains unclear, why Pringsheim later sent the evaluation report. All three external candidates recommended the award of the degree. SCS obtained the D.Sc. degree in 1933 and was honoured with the Griffith Memorial Prize. It seems that Raman and SCS did not have a cordial relation. One of SCS's associates, G. S. Kastha, wrote: "Prof. Raman did not encourage him and casually pointed out that only a scientist who was born as a genius could make any important fundamental discovery. At that time, for some reasons, ${ }^{5}$ Prof. Raman was disgusted with Bengali research workers" (Kastha, 1984, pp. 5-12).

Before Raman left for IISc Bangalore he handed over the charge of instruments belonging to Palit Laboratory to SCS and before leaving Kolkata forever, he offered SCS a job at IISc. SCS declined as he was offered the same salary. D. M. Bose, Raman's successor at IACS advised SCS to work on Raman effect. This work had been discontinued after Bose left the University to join Bose Institute as its Director. In 1938, M. N. Saha became his successor and under him Sirkar started working in the area of nuclear physics. He also studied cosmic rays with a countertelescope.

Until 1942, SCS had 50 publications, but still no permanent position. In 1943, he was offered temporary Readership for one year at the IACS. In 1945, he was appointed as Lecturer at the Science College, University of Calcutta. In 1948, he joined as Professor of Physics and Head of the Department of Optics at the IACS. SCS went abroad for the first time in 1954 to visit different institutions in the USA and England. In UK he met David Schonberg from Cambridge. He also visited laboratories of P. M. S. Blackett,

\footnotetext{
${ }^{5}$ G. S. Kastha did not seem to be aware that in 1932-1933, there was dispute between a small group of Bengalis, who under M. N. Saha's leadership forced Raman to resign the Presidentship of the IACS. The group was of the opinion that C. V. Raman, who is Director of the Indian Institute of Sciences, Bangalore; controls the affairs of the Association. Also, Raman was accused of not supporting Bengali researchers. For more detail see, The Illustrated Weekly of India, Sept 24, 1989; Chatterjee, Saha and C. V. Raman, 1995; Venkataraman, 1994; Biswas, 2013, pp. 61-77.
}

Imperial College of Science in London, and W. C. Price, King's College of London (Kastha 1984, pp. 5-12).

SCS occupied various positions and honoured with many awards during his lifetime. Notable ones are like Griffith Memorial Prize, 1934; Sir Asutosh Mookerjee Gold Medal, 1935; Fellow - National Institute of Sciences of India (now INSA), 1942; Professor of physics head of department of optics, 1948; Acting Director IACS, Dec. 8, 1958 to Dec. 10, 1959, Professor Emeritus, IACS, 1964 onwards; President of the IACS Council (1973-1974) and Member of Board of Editors and Secretary-Indian Journal of Physics. SCS was a specialist in crystal structure. His scientific papers dealt with Raman effect, crystal structure, Kerr effect, measurement of permanent electric movement of molecules and on cosmic rays (Chattopadhyay, 2002, p. 1366). SCS died on Feb. 15, 1983.

\section{IACS and changing pattern of management}

In 1938, members of the management committee of IACS Nilratan Sirkar (President), U. N. Brahmachari, M. N. Saha and S. K. Mitra thought about relocating the laboratories at some other place (AR-IACS 1938). In the beginning of the 1940s buildings and laboratories were in bad condition. Repairing was not possible as the building material was too expensive during the WWII (AR-IACS (1941) U. N. Brahmachari, in his Presidential address 'The beginning and the future of the IACS' on 6th March, 1943 suggested to sell off the place and build a building for the IACS elsewhere so that fields of research can be expanded. He proposed the reintroduction of subjects which were being taught in the early 20th century. He also suggested cooperation with other institutions in Calcutta. His plan was not realized till the end of the war. In 1943, SCS was appointed as reader in physics. He and his associates B. M. Bishui, S. B. Sanyal, N. N. Saha and R. R. Rudra started working on Raman effect and X-ray analysis of jute fibre. The latter one was a project at the University of Calcutta, sanctioned to M. N. Saha by the Indian Central Jute Committee and he transferred it to IACS. In the same year SCS delivered a lecture on "Cosmic rays", and B. M. Bishui on "Extra Laue spots" (AR-IACS, 1943).

K. Banerjee, appointed as M. L. Sircar Professor in 1943 continued his research on X-rays, Raman effect, spectroscopy and magnetism. He was assisted by two research 
assistants and five research scholars. IACS list of publications for the year 1944 mentions six papers published by them (AR-IACS, 1944) out of which two by S. C. Sirkar et al., (Sarkar and Sanyal, 1943; Sirkar et al.1944). In 1945, out of ten, three articles were of S. C. Sirkar, with Bhuban Mohan Bishui, a scholar of Banerjee's team (Sirkar and Bishui, 1945a, 1945b, 1945c).

U. N. Brahmachari proposed expansion of research fields and a new place for the Association was realized by the efforts of M. N. Saha, since Brahmachari died on Feb. 6, 1946 (AR-IACS, 1946). Annual Report of 1946 mentions the appointment of five new scholars (three from Bengal, one from Madras and one from Travancore). Miss Lily Mathew from Travancore seems to be the first woman scholar to ever join IACS. Eight more researchers were granted permission to work under M. L. Sircar. In spite of political unrest, twelve articles were published out of which one was by Sirkar and Bishui (1946).

The Development plan of Association was approved by the Government of India in 1946. According to the plan five new departments to be created were: General physics and optics; theoretical physics; organic; inorganic and physical chemistry. S. C. Sirkar and S. R. Palit were appointed as professor of general physics and optics and physical chemistry respectively (AR-IACS, 1947-1948). Physics department had sub departments such as department of X-rays and magnetism and department of optics. The X-rays department had 12 scholars; whereas B. M. Bishui and M. V. Rao were appointed as senior and junior research scholars for the department of optics. They joined on Dec. 15, 1947, and Feb. 7, 1948, respectively. One more junior research scholar was appointed on June 1, 1948. Permission was granted to Nirmal Chandra Majumdar (research assistant under CSIR scheme) and Saroj Bandhu Sanyal (professor of physics, Presidency College, Calcutta) to work under SCS (AR-IACS, 19471948).

\section{S. C. Sirkar and ups and downs of department of optics}

Annual report of IACS under the section "Work done in the Optics Department" during the year 1947-1948 reports that it took a long time to appoint research scholars leaving only a short period of 3-4 months to initiate research activities. The work done during this pe- riod comprised mainly of investigations on the Raman effect in various compounds under different temperatures like (i) B. M. Bishui's work on the polarisation of Raman lines in different solvents, (ii) M. V. Rao's Raman spectrum of propyl-bromide in gaseous state (iii) N. C. Majumdar's study on the Raman spectra of organic sulphur compounds (AR-IACS, 1947-1948).

The foundation stone of the Research Laboratory building at Jadavpur was laid on September 26, 1948 by Bidhan Chandra Roy, Chief Minister of West Bengal. In 1948, a number of appointments were made in the optics and physical chemistry departments. The department of optics comprised of S. C. Sirkar (professor of physics), B. M. Bishui (research officer), Samarendra Nath Sen (laboratory technician), Atul Chandra Choudhuri (laboratory assistant), M. V. Rao (senior research scholar), Gouranga Sundar Kastha and Anil Krishna Roy (junior research scholar), Madhab Chandra Chatterji (clerk typist) and Hermanta Kumar Sirkar (laboratory attendant) (AR-IACS, 1948-1949). SCS and his associates B. M. Bishui, S. B. Sanyal, B. B. Majumdar, N. C. Majumdar, G. S. Kastha published ten articles in the Indian Journal of Physics. Five out of ten publications were from Bishui (AR-IACS, 1948-1949).

We find from the AR-IACS for the year 1950-51 that M. N. Saha managed to sell the old IACS at the cost of 7 lakh rupees to the Government of West Bengal. The Association was shifted from Bow Bazaar to Jadavpur. The investigations carried out at the department of optics were in the fields of (i) Brillouin component in light scattered by crystals, (ii) Origin of new low-frequency Raman lines of organic crystals, (iii) Raman spectra of organic compounds in the vapours state, (iv) Ultraviolet absorption spectra of organic compounds in the solid state at low temperature and (v) Absorption of UHF Radio waves in liquids and binary liquid mixtures. Thirteen papers were published by SCS and his associates. In the same year, SCS delivered a lecture on "Fundamental particles". From the Annual Report for the year 1951 we observed that the Association still did not have the transformer, rectifier etc. for the supply of direct current hampering the dependent research work. However, it did not affect Sirkar's group which continued its investigations on the earlier mentioned topics. Its members - S. C. Sirkar, S. N. Sen, A. R. Deb, H. N. Swamy, A. K. Ray, B. M. Bishui, G. S. Kastha and T. A. Hariharam published 14 articles 
during the year (AR-IACS, 1951-1952).

The next change in the history of the Association was the creation of a paid post for the Director. M. N. Saha joined as the first Director of the IACS on January 1, 1953. P. Ray worked as Acting Director on an honorary capacity from 1947 onwards (AR-IACS, 1952-1953). Under Saha's leadership, the 25th anniversary of the discovery of Raman effect was celebrated. He highlighted the importance of the discovery, whereas SCS narrated the steps which led to the discovery. ${ }^{6}$ SCS and his associates carried on investigations on Raman spectra, ultraviolet absorption, depolarisation of Rayleigh scattering in non-polar and polar molecules, absorption of Ultra High Frequency radio waves in organic liquids and structure of resonance line of sodium filtered through sodium vapors. Thirteen papers were published on these topics, while six were reported to be in press (AR-IACS, 1952-1953).

In 1953, SCS was appointed as M. L. Sircar Professor of Physics, after K. Banerjee resigned and joined the University of Allahabad (AR-IACS, 1953-1954). Additionally Department of Optics started working on the absorption of microwaves by organic liquids, and cosmic rays. SCS along with D. K. Ghosh and N. K. Roy published two papers whereas his associates published fourteen articles. A female scholar, Miss Usha Rani Biswas started working on the ultra violet absorption spectra (AR-IACS, 19531954).

For the year 1954-55, the Association had asked for Rs. 244300, but received only Rs. 160000/. Consequently, it was not possible to buy some of the important equipment. According to the Report: "A number of precision equipment, including a glass blowing lathe, were ordered from the USA, and in this work the Association received considerable help from S. C. Sirkar who had recently been to the USA and studied the workshop practice and organization in that country" (AR-IACS, 1954-1955).

On the invitation of F. Cleveland SCS visited Illinois Institute of Technology, Chicago in the middle of 1950s, his only visit abroad. He worked with F. L. Voelz and F. Cleveland and published one paper on Infrared spectra and structure of 2,6-Dioxaspiro $(3,3)$ heptane. He worked with F. L. Voelz and F. Cleveland and published one paper on Infrared spectra and structure of 2,6-Dioxaspiro $(3,3)$ heptane ( \& Voelz et al.1955).

\footnotetext{
${ }^{6}$ AR-IACS, 1952-1953. The wording of the Report is same as published in Nature 171(1953):504.
}

Prof. Sirkar availed himself of this opportunity and spent about six months working at the Spectroscopy Laboratory of the Illinois Institute of Technology and visiting a number of research institutions both in the USA and the UK. At the request of the Institute of Nuclear Physics, he visited the University Research Reactor at Rayleigh-Durham, set up by Prof. Clifford E. Beck of the University of North Carolina" (AR-IACS, 1954-1955).

In 1956, S. C. Sirkar's main supporter, M. N. Saha died and Indian Government had started the five-year plan during Saha's time. The Council of Scientific and Industrial Research (CSIR) sanctioned different projects at the IACS. SCS was investigator-in-charge of the investigation of crystal structure of frozen organic liquids at low temperatures (AR-IACS, 1955-1956). This project continued until 1962-1963 with a meager grant of Rs. 2157/ in 1959 to Rs. 4041.29 in 1962. SCS had contact with foreign scientists as well. In 1954, G. Herzberg FRS, National Research Council, Canada, was awarded Joykissen Mookerjee Gold Medal and he delivered two lectures on "Spectroscopy and Molecular Structure on January 11 and 12, 1957. It must have been a good experience for Herzberg to meet S. C. Sirkar as he wrote to G. S. Kastha on Dec. 23, 1983: "I met Professor Sirkar for the first time on my first trip to India in 1956 and was much attracted by his personality." W. C. Price, FRS, University of London wrote to G. S. Kastha, on Jan. 19, 1984 "I am sorry to hear of Professor Sirkar's death. I knew him many years ago and greatly respected his contribution to Indian Molecular Spectroscopy."

The construction of the first floor of the main research building started at the end of 1956 and was completed in 1957. Deb Kumar Mukherjee, T. N. Misra, N. K. Roy, S. G. Biswas, G. S. Kastha, G. S. R. Krishna Murti, S. B. Banerjee and S. B. Roy were Sirkar's colleagues. They published ten papers out of which two were by SCS with his associates (AR-IACS, 1957-1958).

\section{SCS as acting director}

S. N. Bose was appointed President of the IACS in September 1958 and, Sirkar as the acting Director on Dec. 8, 1958. Both of them started under stringent financial conditions. For instance, "The Finance Committee and the 
Council gave the matter their most serious thoughts and expressed the view that the sum of Rs. 6.00 lakhs [granted by the Government] would be wholly inadequate for carrying on the Association's work even on 1957-58 level" (AR-IACS, 1958-1959). For about a year SCS worked as acting Director and on Dec. 11, 1959, K. Banerjee, then head of the physics department of the University of Allahabad, was appointed as Director. In 1959, department of optics was working on six different topics related to spectroscopy, absorption of microwaves in organic liquids and $\mathrm{X}$-ray analysis of structure of organic compounds at low temperature and published eleven articles. One of them was by SCS entitled: "Infrared absorption spectra of diamonds of different types" (Sirkar, 1960). The members of the group were J. K. Roy, T. N. Misra, Monomohan Majumder, S. G. Biswas, G. S. R. Krishna Murti, T. J. Bhattacharyya, G. S. Kastha, S. B. Banerjee, K. C. Medhi, S. C. Sirkar, Krishna Kumar Dev and S. K. Sen (AR-IACS, 1959-1960).

In 1960, there were eight research departments and optics department was working on seven different topics. The study of wing of the Rayleigh line with selfrecording grating spectrophotometer and Singlet $\rightarrow$ triplet absorption in substituted benzene compounds in different states were new areas. In this year thirteen papers were published by the members of the group, out of which two were by SCS and his students. In 1962, two of Sirkar's students went abroad: M. M. Majumder was appointed as research associate in the Spectroscopy Laboratory, Illinois Institute of Technology, Chicago and S. B. Roy as research assistant, University of Pennsylvania, Philadelphia.

SCS was sanctioned a grant of Rs. 5309.41 to work under Retired Scientists Scheme of the Association after retirement. According to the AR of the year 1963-64:

At the beginning of the year Prof. S. C. Sirkar, ..., M. L. S, Professor of Physics and Head of the Department of Optics retired from service. Moreover, almost all of the senior research workers left the Department on receiving awards of Post-doctoral fellowships from abroad. Also, the Department had to function without a Research Officer and Research Assistant for about the whole of the year and the post of Reader remained unfilled. All these put a great handicap on the research activities of the department.
However, the research continued in the areas of Raman and infrared spectra, ultraviolet absorption spectra, measurement of dielectric loss and relaxation times in organic liquids and crystal structure of aromatic molecules with limited staff.

\section{Continuation of Sirkar's legacy}

G. S. Kastha writes that S. C. Sirkar's associates published about 250 research papers. Eighteen research scholars of optics department were selected for the doctorate degrees from 1948 up to his retirement in 1963. Six more researchers either did Ph.D. or D.Sc. under his guidance after his retirement (Kastha, 1984, pp. 5-12). The list of students who did D.Sc. or D.Phil. (Science) with their research titles based on the Annual Reports of the IACS is shown below. The publication "A Century: Indian Association for the Cultivation of Science" only provides a list of students who completed D.Sc. or D. Phil. (Science) in the department of optics until 1974 and not the title of their thesis (Ghatak et al, 1976, pp. 234-235).

In 1964-65, eight departments of the Association continued their research activities. G. S. Kastha was appointed as reader and placed in-charge of the department. CSIR appointed Gobinda Basu as pool officer for the department of optics. SCS was given a grant of Rs. 8099 under Retired Scientists' Scheme. On the recommendation of the Council in a meeting in Sept. 1964, SCS was appointed an Emeritus professor "in recognition of his valuable services to the Association and his contribution to science”. Department of optics carried out researches on Raman and infrared spectra, ultraviolet absorption spectra and luminescence spectra and microwave absorption and dielectric relaxation. The department published seven papers out of which two were by SCS et al and five by G. S. Kastha and his associates. SCS with his collaborators investigated the Raman spectra of organic molecular crystals at low temperature $\left(200^{\circ} \mathrm{C}\right)$ and extended the investigations to liquid hydrogen temperature.

K. Banerjee retired from the post of Director on October 1, 1965 and B. N. Srivastava was appointed as acting Director. In the same year G. S. Kastha was appointed as professor of physics. On account of emergency, posts of reader, research officer and research assistant remained vacant. Due to strict import restrictions imposed by Government of India, spare parts of the existing instruments 
Scholars who did D.Sc. or D. Phil. (Sc.) under S. C. Sirkar.

\begin{tabular}{|c|c|c|}
\hline $\begin{array}{c}\text { IASC } \\
\text { AR-Year }\end{array}$ & Name & Title \\
\hline $1951-52$ & Samarendra Nath Sen & $\begin{array}{l}\text { Study on the absorption of ultra-high frequency radio waves by } \\
\text { polar molecules }\end{array}$ \\
\hline $1953-54$ & A. K. Ray & $\begin{array}{l}\text { On the origin of low frequency Raman lines in crystals of some } \\
\text { aromatic organic compounds }\end{array}$ \\
\hline \multirow[t]{2}{*}{$1954-55$} & Saroj Bandhu Sanyal & Investigation of Raman spectra \\
\hline & Adhir Ranajn Deb & $\begin{array}{l}\text { Ultraviolet absorption spectra of organic substances in different } \\
\text { states }\end{array}$ \\
\hline $1955-56$ & H. N. Swamy & title unknown \\
\hline $1956-57$ & $\begin{array}{l}\text { Sushil Kumar } \\
\text { Chowdhury }\end{array}$ & $\begin{array}{l}\text { Investigation on structure of jute fibre and its derivatives with the } \\
\text { help of X-rays }\end{array}$ \\
\hline \multirow[t]{2}{*}{$1957-58$} & $\begin{array}{l}\text { Dinesh Chandra } \\
\text { Biswas }\end{array}$ & $\begin{array}{l}\text { Investigation on the Raman spectra and fluorescence of organic } \\
\text { compounds }\end{array}$ \\
\hline & Dilip Kumar Ghosh & $\begin{array}{l}\text { Investigation in the absorption of ultra-high frequency radio wave } \\
\text { and micro-waves in polar liquids }\end{array}$ \\
\hline \multirow[t]{3}{*}{$1959-60$} & S. B. Banerjee & title unknown \\
\hline & G. S. R. Krishna Murti & $\begin{array}{l}\text { X-ray analysis of crystal structure of organic compounds at different } \\
\text { temperatures" }\end{array}$ \\
\hline & Smriti Bhusan Roy & $\begin{array}{l}\text { Ultra-violet absorption on spectra of frozen solution of some } \\
\text { aromatic compounds }\end{array}$ \\
\hline $1960-61$ & $\begin{array}{l}\text { Monomohan } \\
\text { Majumder }\end{array}$ & $\begin{array}{l}\text { Studies on the influence of intermolecular field on Raman and } \\
\text { infrared spectra and Rayleigh scattering }\end{array}$ \\
\hline \multirow[t]{3}{*}{$1961-62$} & G. S. Kastha & $\begin{array}{l}\text { Investigations on the influence of intermolecular field on Raman } \\
\text { spectra and the structure of resonance radiation of some elements } \\
\text { transmitted by their vapours }\end{array}$ \\
\hline & S. G. Biswas & X-ray analysis of frozen organic liquids at low temperature \\
\hline & S. K. Sen & $\begin{array}{l}\text { Study of the electronic spectra of some aromatic compounds in the } \\
\text { states of aggregation }\end{array}$ \\
\hline \multirow[t]{3}{*}{$1963-64$} & $\begin{array}{l}\text { Tridibendra Narayan } \\
\text { Misra }\end{array}$ & $\begin{array}{l}\text { Investigation on the electronic spectra of some aromatic compounds } \\
\text { in different states }\end{array}$ \\
\hline & Krishna Kumar Deb & $\begin{array}{l}\text { Investigation on Raman and infrared spectra of some organic } \\
\text { compounds }\end{array}$ \\
\hline & Joydeb Kumar Roy & $\begin{array}{l}\text { Investigation on the singlet, triplet transition in some substituted } \\
\text { benzene compounds }\end{array}$ \\
\hline $1964-65$ & Narendra Kishore Roy & $\begin{array}{l}\text { Studies on the Raman spectra of some organic monomers in } \\
\text { different states and on the Raman and infrared spectra for their } \\
\text { polymers }\end{array}$ \\
\hline $1968-69$ & Tarak J. Bhattacharyya & $\begin{array}{l}\text { Investigations on the dielectric relaxation of some organic molecules } \\
\text { in solutions }\end{array}$ \\
\hline $1969-70$ & D. K. Mukherjee & $\begin{array}{l}\text { Investigations on Raman spectra and Infrared absorption Spectra of } \\
\text { some organic Compounds in different states }\end{array}$ \\
\hline $1971-72$ & P. K. Bishui & $\begin{array}{l}\text { Investigations of the influence of intermolecular field on the Raman } \\
\text { and infrared spectra of some organic molecules in different states }\end{array}$ \\
\hline
\end{tabular}


as well as the purchase of new instruments were not possible. This hampered research work in the department of optics (AR-IACS, 1965-1966). Only nine articles were published, two of them by SCS and others (Mukherjee \& Bishui et al.1965a, 1965b).

During the year 1966-67 too, the posts remained vacant and no research equipment could be purchased due to the same import policy issues. Due to deferring of the Fourth Five Year Plan no new line of investigation could be undertaken. However, SCS could investigate the Raman spectra of methylene chloride, chloroform and carbon tetrachloride in the solid state at low temperature under the grant provided under "Retired Scientist Scheme (Bishui \& Mukherjee et al. 1967). It was expected that the investigations will throw light on the effect of change of state and temperature on the vibrational modes of molecules. P. K. Bishui and S. K. Nanday (honorary research fellows) continued their researches under SCS, on Raman spectra and published research papers (Sirkar \& Bishui, 1968a, 1968b; Bishui \& Mukherjee et al., 1967).

In 1969, Infrared spectrometer remained defective for some time. The research activities were confined to Raman and infrared absorption spectra, ultraviolet absorption spectra and microwave absorption and dielectric relaxation. Projects proposed in the 4 th five year plan could not be undertaken due to lack of instruments and personnel. Only three articles were published during the year (AR-IACS, 1969-1970).

\section{Epilogue}

SCS lived long enough to see the ups and downs of the department of Optics. It must have been a feeling of satisfaction for him to see that a handful of his students dominated the IACS by the end of 1970s. For instance, the academic staff consisted of G. S. Kastha, S. B. Roy, S. B. Banerjee, T. N. Misra and D. K. Mukherjee. In 1984 a special symposium on Molecular Spectroscopy was held at the IACS and the proceedings of the seminar were published in two parts in Indian Journal of Physics, vol. 58, 1984 (Figure 2). The driving force behind this event was his student G. S. Kastha.

D. K. Ghosh, one of Sirkar's students wrote: "We may not be students of a 'big' Professor, but are proud of having a true and a very human Professor as our Master" (Ghosh, 1984, pp. 38-39). This indicates little importance given

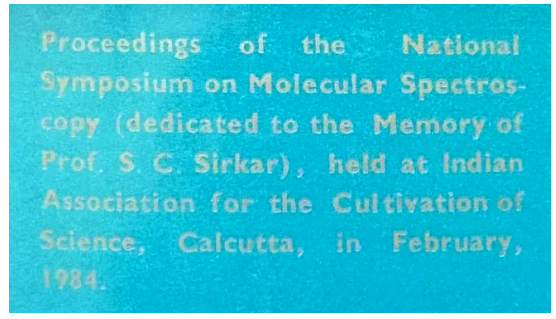

Figure 2 Dedication to S. C. Sirkar by the IACS and Indian Physical Society; Credit: IACS.

to scientists who spend time in supporting their students than discovering something new. We as historians of science should write more on - how and in which way a scientist influenced the development of science in a country; rather than focusing on the discoveries and inventions. This can help to understand the overall development of science in social and political context.

\section{Acknowledgement}

I am thankful to S. C. Roy, Editor-in-Chief, Science and Culture for commenting and correcting the early version of this paper. Thanks are due to Michael Komorek, University of Oldenburg, Germany, for providing research facilities. Last but not the least I thank K. Ramasubramanian, Editor and M. Narayan, Associate Editor, IJHS for the editorial work.

\section{Bibliography}

[1] Annual Report of the IACS, Calcutta, 1938, 1941, 1942, 1943, 1944 and 1946.

[2] Annual Report of the IACS, Calcutta, 1947 to 1974.

[3] Bishui, P. K., Mukherjee, D. K. and Sirkar, S. C. The Raman Spectra of $\mathrm{CH}_{2} \mathrm{Cl}_{2}$, and $\mathrm{CCl}_{2}$, and $\mathrm{CCl}_{4}$ at $64^{\circ} \mathrm{K}$, Indian J. Phys. 41(1967): 553-558.

[4] Biswas, A. K., Raman, Krishnan and the IACS, Indian Journal of History of Science(IJHS) 48(2013): 61-77.

[5] Chatterjee, S. Meghnad Saha and C. V. Raman-Fact and Fiction, Indian Physical Society, Diamond Jubilee Number 43-47, 1995. 
[6] Chattopadhyay, A. Biographical Dictionary of Indian Scientists - From Ancient to Contemporary, Rupa Co., New Delhi, 2002.

[7] Ghatak, U. R. Mukherjee, S. C., Chaudhuri, A. K. et al. A Century: Indian Association for the Cultivation of Science, Calcutta, 1976.

[8] Ghosh, D. K. In memory of my beloved teacher, In: Homage to Professor Sukumar Chandra Sirkar, Kastha, G. S. (ed.). Indian Association for the Cultivation of Science, Calcutta, 1984

[9] Kastha, G. S. Sukumar Chandra Sirkar (1893-1983), Biographical Memoirs of Fellows of INSA 12(1983): 10-20.

[10] Kastha, G. S. A short life sketch of Prof. Sukumar Chandra Sirkar, In: Homage to Professor Sukumar Chandra Sirkar, Kastha, G S (Ed.), Indian Association for the Cultivation of Science, Calcutta, 1984.

[11] Kastha, G. S. Sukumar Chandra Sirkar - The Man, In: Homage to Professor Sukumar Chandra Sirkar, Indian Association for the Cultivation of Science, Calcutta, 1984

[12] Lonsdale, K. and Bhabha, H. J. Kariamanikkam Srinivasa Krishnan, Biogr. Mem. Fell. R. Soc. Lond. 13(1967): 245-255

[13] Mallik D. C. V. and Chatterjee S. Kariamanikkam Srinivasa Krishnan - His Life and Work, University Press (India) Prv. Ltd., Hyderabad, 2012.

[14] Mukherjee, D. K., Bishui, P. K. and Sirkar, S. C. On the Infrared Spectra of $\beta$-Fluoro- and o-, m- and pChloro Toluene in the Vapour State, Indian J. Phys., 39(1965a): 537-551.

[15] Mukherjee, D. K., Bishui, P. K. and Sirkar, S. C. Singlet $\rightarrow$ Triplet Absorption in Meta and Parachlorotoluene, Indian J. Phys., 39(1965b): 313-317.

[16] Raman, C. V. and Sirkar, S. C. Disappearance of Reversal of the Kerr Effect, Nature, 121(1928): 794.

[17] Roy S. C. and Singh R. D. M. Bose: A Scientist Incognito, Bose Institute Publications, Calcutta, 2017.
[18] Roy, S. C. and Singh, R. D. M. Bose and Cosmic Ray Research, Indian J. Hist. Sci. 82(2016):364-377.

[19] Singh, R. Nobel Prize Nominator Sisir Kumar Mitra F.R.S.: His Scientific work in International Context, Shaker Verlag, Aachen, 2014.

[20] Singh, R. D. M. Bose: His Scientific work in International Context, Shaker Publisher, Aachen, 2016

[21] Singh, R. Bidhu Bhushan Ray: A Pioneer of X-ray Spectroscopy, Shaker Verlag, Aachen, 2017.

[22] Singh, R. Sisir Kumar Mithra. Scientific Achievements and the Fellow of the Royal Society London, Indian J. Hist. Sci., 52(2017): 407-419.

[23] Singh, R. and Roy, S. C. Coming of age-Bose Institute under D.M. Bose, Sci. Cult., 83(2017): 364-379.

[24] Singh, R. B. B. Ray and Controversy over the Spectral Raman-lines, Indian J. Hist. Sci., 52(2017): 343-350.

[25] Singh, R. B. B. Ray and the Glories, Sci. Cult., 83(2017): 221-224.

[26] Singh, R. B. B. Ray under the Influence of C. V. Raman and M. N. Saha, Sci. Cult, 83(2017): 84-91.

[27] Sirkar, S. C. and Bishui, B. M. Fluorescence of Dipropyl Ketone at low temperatures, Nature 156(1945a): 333-334.

[28] Sirkar, S. C. and Bishui, B. M. On the Raman Spectra of Ethylene dibromide and Dichloro ethylene in the Solid state, Indian J. Phys., 19(1945c): 24-33.

[29] Sirkar, S. C. and Bishui, B. M. Raman Spectra of a few Aliphatic Ketones at low Temperatures, Indian J. Phys., 20(1946): 35-42.

[30] Sirkar, S. C. and Bishui, B. M. Raman Spectra of Acetone and Diethyl ketone in the Solid state, Sci. Cult., 11(1945b): 273

[31] Sirkar, S. C. and Bishui, P. K. On the Assignment of some Vibration Frequencies of a few Substituted Benzenes, Indian J. Phys., 42(1968a): 1-10.

[32] Sirkar, S. C. and Bishui, P. K. On the Raman and Infrared Spectra of Benzoyl chloride in Different state, Indian J. Phys., 42(1968b): 243-253. 
[33] Sirkar, S. C. and Sanyal, S. B. Influence of Temperature on the Intensities of Raman Lines due to some Organic liquids, Indian J. Phys., 17(1943): 309-315.

[34] Sirkar, S. C. Infrared absorption Spectra of Diamonds of different Types, Indian J. Phys., 34(1960): 13-19.

[35] Sirkar, S. C. On the Laue Photographs of Iridescent crystals of Potassium chlorate, Indian J. Phys., 5(1930): 337-343.

[36] Sirkar, S. C. Reminiscences of my Association with Prof. C.V. Raman, In: Chandrasekhara Venkata Raman Birth Centenary, Basak, A, Basu, J, Basu, D, et al. (Eds.), The Calcutta Municipal Corporation, Calcutta, 1988.

[37] Sirkar, S. C. The Electric Moment of $\mathrm{CH}_{3} \mathrm{Cl}, \mathrm{C}_{2} \mathrm{H}_{5} \mathrm{Cl}$ and $\mathrm{CHCl}_{3}$, Indian J. Phys., 3(1928a): 197-208.

[38] Sirkar, S. C. The Kerr Effect in viscous Liquids due to Radio Frequency oscillating Field, Indian J. Phys., 3(1928b): 409-424.

[39] Sirkar, S. C., Saha, N. N. and Rudra, R. N. X-ray Analysis of Jute fibre of Different Qualities under various Conditions, Proc. Nat. Inst. Sci. India 10(1944):325331.

[40] Sirkar, S. C., Voelz, F. L. and Cleveland, F. F. Raman and Infrared Spectra and Structure of 2,6-Dioxaspiro (3,3) Heptane, J. Chem. Phys., 23(1955): 1684-1685.

[41] The Illustrated Weekly of India, Sept 24, 1989.

[42] Venkataraman, G. Journey into Light - Life and Science of C.V. Raman, Penguin Books India (P) Ltd., New Delhi, 1994. 